\title{
Sonographic features of the testicular adrenal rests tumors in patients with congenital adrenal hyperplasia: a single- center experience and literature review
}

$\mathrm{Li} \mathrm{Ma}^{1+}$, Yu Xia ${ }^{1+}$, Linlin Wang ${ }^{1,2}$, Ruifeng Liu' ${ }^{1}$ Xuepei Huang ${ }^{1}$, Tiantian Ye ${ }^{1}$, Li Zhang ${ }^{1}$, Qingli Zhu', Jianchu Li ${ }^{1}$ and Yuxin Jiang ${ }^{1 *}$

\begin{abstract}
Purpose: Testicular adrenal rests tumor (TART) is a rare kind of benign tumor in the testis. It usually occurred secondary to congenital adrenal hyperplasia (CAH), a hormonal disorder caused by hydroxylase deficiency. As the first-line examination method, ultrasound provides crucial diagnostic information for TART, although misdiagnosis to malignancy is quite common because of its rare prevalence. We aimed to summarize the sonographic manifestations of TART to improve the diagnostic accuracy and specificity.
\end{abstract}

Methods: Eight CAH patients with TART identified by ultrasound in our medical center were retrospectively reviewed. Clinical and hormonal profile, semen analysis and treatment choices were collected. Sonographic examinations were performed at the first evaluation and interpreted by experienced radiologists individually. All patients received regular follow-up, and 5 patients undertook repeated scrotal ultrasound. A literature review of TART in CAH patients was conducted, with 123 patients from 23 articles since 1990 included.

Results: A total of 8 patients aged between 4 to 27 years old were enrolled. 7 of 8 (87.5\%) patients exhibited bilateral testicular lesions. The sizes of the testicular lesions were between $0.18 \mathrm{ml}$ to $5.68 \mathrm{ml}$, and all showed a clear boundary. 10/15 (66.7\%) lesions were homogenously hypoechoic, 4/15 (26.7\%) were heterogeneously isohypoechoic, and 1/15 (6.7\%) were homogenously isoechoic. 10/15 (66.7\%) lesions were hyper-vascular. The longitudinal follow-up of 5 patients showed testicular lesions changed in terms of size, echogenicity, and vascularity after steroid treatment. A potential correlation may exist between ACTH levels and tumor size $(p=0.066)$. From the literature review, 100/123 (81\%) patients got bilateral lesions, and 95\% of them were located near the mediastinum. 80/103 (78\%) lesions exhibited a clear boundary, and predominant lesions (74\%) were hypoechogenic. Vascularity was with great diversity. Seventy-nine lesions of 44 patients were followed-up by scrotal ultrasound, among which 29 (37\%) remained unchanged, 29(37\%) shrank, and 21(27\%) disappeared.

Conclusions: Key sonographic characteristics of TART are: resembled lesions on both testes, located near the mediastinum, clear boundary, and changed in size or echogenicity after steroid treatment. These features can help radiologists to make an accurate diagnosis of TART.

Keywords: Testicular adrenal rests tumor, Ultrasound, Congenital adrenal hyperplasia

\footnotetext{
* Correspondence: yuxinjiangxh@163.com

†Li Ma and Yu Xia contributed equally to this work.

'Department of Ultrasound, Peking Union Medical College Hospital, Chinese

Academy of Medical Sciences, Shuaifuyuan 1, Dongcheng District, Beijing

100730, China

Full list of author information is available at the end of the article
}

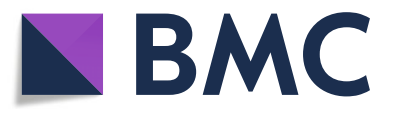

(c) The Author(s). 2019 Open Access This article is distributed under the terms of the Creative Commons Attribution 4.0 International License (http://creativecommons.org/licenses/by/4.0/), which permits unrestricted use, distribution, and reproduction in any medium, provided you give appropriate credit to the original author(s) and the source, provide a link to the Creative Commons license, and indicate if changes were made. The Creative Commons Public Domain Dedication waiver (http://creativecommons.org/publicdomain/zero/1.0/) applies to the data made available in this article, unless otherwise stated. 


\section{Introduction}

Testicular adrenal rests tumor (TART) is a rare kind of benign tumor in the testis, which occurs mainly secondary to congenital adrenal hyperplasia $(\mathrm{CAH})$, an autosomal recessive disorder with a deficit of enzymes related to glucocorticoids synthesis. In over 90\% cases, the deficient enzyme is 21-hydroxylase, while in other cases, the deficient enzyme is 11-hydroxylase [1]. Driven by the negative feedback regulation, the level of adrenocorticotropic hormone (ACTH) increases, leading to the hypertrophy of the adrenal glands, and overproduction of other hormones [2]. During embryonic development, some cells destined to become adrenal glands may nestle within the rete testis because of the close positional relation, known as residual adrenal cells [3]. The reported prevalence of residual adrenal cells in the testes of healthy neonates was $15 \%$, although it is probably underestimated due to technical reasons $[4,5]$. Nowadays, it is believed that TART originates from these residual adrenal cells, and high ACTH levels stimulate these cells to proliferate and form masses. The prevalence of TART in $\mathrm{CAH}$ male patients varies considerably in previous reports, with an increasing prevalence rate observed during and after puberty [6, 7]. Although it is benign, the growing masses would compress the spermatogonium and ductulus efferens, which may lead to irreversible damage and cause infertility [8, 9]. Ectogenous glucocorticoids are used for CAH and TART treatment by suppressing $\mathrm{ACTH}$ production and maintaining the glucocorticoid level [10].

As a safe, convenient, and economic-efficient method, scrotal ultrasound is usually recognized as the first-choice for TART screening in clinical practice. It is indicated that ultrasound and MRI have comparable sensitivity in the detection of TARTs [11]. Caused by its low prevalence, only limited literature has reported the sonographic features of TART; most radiologists do not recognize it and misdiagnose it to malignant tumors, which may lead to unnecessary testectomy [12]. Here, to give a thorough sonographic description of TART, we presented 8 cases of TART in our hospital, and conducted a literature review of the previous reports.

\section{Methods}

\section{Patients}

This is a retrospectively study, where the inpatient and outpatient databases from January 2004 to December 2017 in Peking Union Medical College Hospital were reviewed to identify patients diagnosed with congenital adrenal hyperplasia. In all patients, a diagnosis of 21hydroxylase deficiency or $11 \beta$-hydroxylase deficiency was confirmed by DNA analysis. Scrotal ultrasound must be performed at the first evaluation. TART was diagnosed by either pathological examination or clinical diagnostic criteria that testicular lesions had a good response to hormonal therapy. The demographical, clinical, hormonal, radiological, and pathological data of TART patients before and after treatment were collected. Patients were treated with either dexamethasone or hydrocortisone, and they were asked to come back after treatment for 6 months, when repeated hormonal and/or ultrasound examinations were performed. Written informed consent was signed by all patients or their legally authorized representatives with regard to the use of patients' data for study propose.

\section{Semen analysis}

Samples of sperm were collected by masturbation after 3 to 5 days of sexual abstinence. Sperm concentration and motility were assessed by a superimposed image analysis system, in accordance with the World Health Organization recommendations [13]. According to WHO recommendations, aspermia was defined as the inability to deliver semen, and azoospermia defined as the absence of spermatozoa in the ejaculate [13].

\section{Ultrasound examination}

Scrotal ultrasound examinations were performed to all CAH male patients before hormone therapy started. Five patients had performed follow-up scrotal ultrasound after steroid therapy started. The ultrasound machine is iU22 machine (Philips Healthcare, Amsterdam, Netherland) equipped with a transducer with a frequency range of 5-12 MHz. All ultrasound examinations were performed by one radiologist with more than 5 years of experience in ultrasound. Both gray-scale and color Doppler images were saved. Then the images were interpreted by another two radiologists specialized in testicular ultrasound individually, and the number, size, shape, boundary, echogenicity, and vascularity of the testicular lesions were carefully recorded in written reports. Lesion shape was divided into "round" "lobular" and "irregular", with a round shape defined as spherical or elliptical, a lobular shape defined as undulating contour, and an irregular shape defined as uneven shape (not round or lobular) [14]."Clear boundary" was defined as the lesion margins that can be clearly defined. The echogenicity was basically divided into hypoechogenicity, isoechogenicity, and hyperechogenicity, as compared to the echogenicity of the normal testis. The echogenicity of the lesion was divided into "homogeneous" and "heterogeneous". "Heterogeneously iso-hypoechoic" is defined as the lesion that is heterogeneous with both isoechogenicity and hypoechogenecity. The evaluation of vascularity was graded according to the Adler's method, that the vascularity was subjectively determined to be absent (grade 0), minimal (grade 1), moderate (grade 2), or marked (grade 3) with 
reference to the normal region of testis, which was considered as moderate vascularity [15].

\section{Literature review}

A thorough literature search was conducted in MEDLINE and Embase databases. The keywords we used for literature search is "testicular adrenal rest tumors ultrasound" within the time range from January 1990 to June 2019. There were 86 results in Pubmed and 150 results in Embase. The inclusion criteria were: [1] Confirmed diagnosis of TART [2]; scrotal ultrasound was performed, and ultrasonographic features were detailedly described (at least lesion size and echogenicity). The excluded criteria were: [1] reviews, irrelevant or overlapped articles [2]; articles that were not able to get access to the full text. Finally, 23 articles were included. Relevant literature was carefully read and compared to our observation.

\section{Statistics}

The correlation of the size of TART and levels of $\mathrm{ACTH}$, luteinizing hormone (LH), follicle-stimulating hormone (FSH), testosterone and age was estimated by Pearson Correlation Coeffient. Lesion size was calculated by the formula: ellipsoid volume $=\pi \times$ length $\times$ width $\times$ height $\div 6$. Bilateral tumors in the same patient were regarded as two individual tumors.

\section{Results}

\section{Baseline characteristics}

In our databases, 48 male patients were identified to be diagnosed as $\mathrm{CAH}$, and all of them underwent scrotal ultrasound examinations. Testicular masses were found by ultrasound in 8 patients, and all of them were diagnosed with TART, among whom three by pathologically confirmed as the residual adrenal gland tissue, and five by meeting the clinical diagnostic criteria that testicular lesions had a good response to hormonal therapy. The baseline characteristics of 8 TART patients were summarized in Table 1. Eight patients were aged from 4 to 27 (median age, 16), with the height from 119 to $169 \mathrm{~cm}$ (median height, $155.7 \mathrm{~cm}$ ) and the weight from 24 to 74 $\mathrm{kg}$ (median weight, $59.1 \mathrm{~kg}$ ). CAH diagnosis was made between 0 and 13 years old. The majority $(7 / 8)$ of patients was caused by $21-\alpha$-hydroxylase deficiency, while only one patient was caused by $11-\beta$-hydroxylase deficiency. Blood pressures of all patients were within the normal range (from $95 / 65$ to $120 / 78 \mathrm{mmHg}$ ). Six of 8 TART patients undertook semen analysis. From semen analysis, one 24-year-old patient suffered from aspermia, another 27-year-old patient had azoospermia, and four patients showed normal results. Among andrological examinations, 7 of $8(87.5 \%)$ patients had palpable testis lesions, 1 of $8(12.5 \%)$ had the varicocele, and no patients showed epididymal cyst and gynecomastia. The hormonal levels showed a broad distribution (Table 2). Five patients with HCG and AFP records showed normal levels of both markers.

\section{Ultrasound manifestations}

From ultrasound results, seven patients had bilateral lesions, whereas one patient had a unilateral lesion; therefore, the total number of lesions is 15 (Table 3). All lesions were located near the testicular mediastinum. The size of the 15 lesions ranged from $0.18 \mathrm{ml}$ to 5.68 $\mathrm{ml}$. The $p$-value between tumor size and ACTH levels was 0.066. No statistically significant correlation of tumor size and age was found $(p=0.328)$, neither did LH $(p=0.285)$, FSH $(p=0.947)$ and testosterone $(p=$ 0.659 ). Same sonographic manifestations were found in bilateral lesions of the same patient. The shapes of the lesions were round (9 lesions) or lobular (6 lesions). All lesions had a clear boundary. Ten lesions were homogeneously hypoechoic, four were heterogeneously isohypoechoic, and one was homogeneously isoechoic. The majority of lesions had marked vascularity (in 10 lesions), while four lesions had minimal vascularity, one showed an absence of vascularity. Calcification was found in two lesions of the same patient.

Five patients received follow-up scrotal ultrasound 6 months after steroid treatment. One patient had a poor hormonal control during the treatment, and sonographic images showed a similar lesion size as before, but a change from the round shape from to lobular shape. Four patients had good hormonal control during the treatment, and testicular lesions reduced significantly in the size and vascularity, without prominent alterations in the shape, boundary, and echogenicity (Fig. 1).

\section{Literature review}

In the literature since 1990, 23 articles were found to have described the sonographic features of TART $[2,7$, 11, 16-34]. One hundred twenty-three patients with a total of 223 testicular lesions were collected. Results were presented in Table 4. 100 (81\%) patients had bilateral lesions, and the majority of them were located near the mediastinum (95\%). Most lesions were round (oval) (75/106, 71\%) or lobular (29/106, 27\%). 80/103 (74\%) lesions had a clear boundary; 164 (74\%) lesions were hypoechoic, $41(18 \%)$ were heterogeneous, and $18(8 \%)$ were with other types, such as hyperechoic. As for vascularity, 39/152 (26\%) lesions exhibited an absence of blood signal, 25/152 (16\%) exhibited a minimal blood supply, 31/152 (20\%) had a moderate blood supply, and $52 / 152$ (34\%) exhibited a marked blood supply. Lastly, 79 lesions of 44 patients were followed-up after steroid therapy, among which 29 (37\%) lesions remained unchanged, 29 (37\%) shrank, and 21 (27\%) disappeared. 


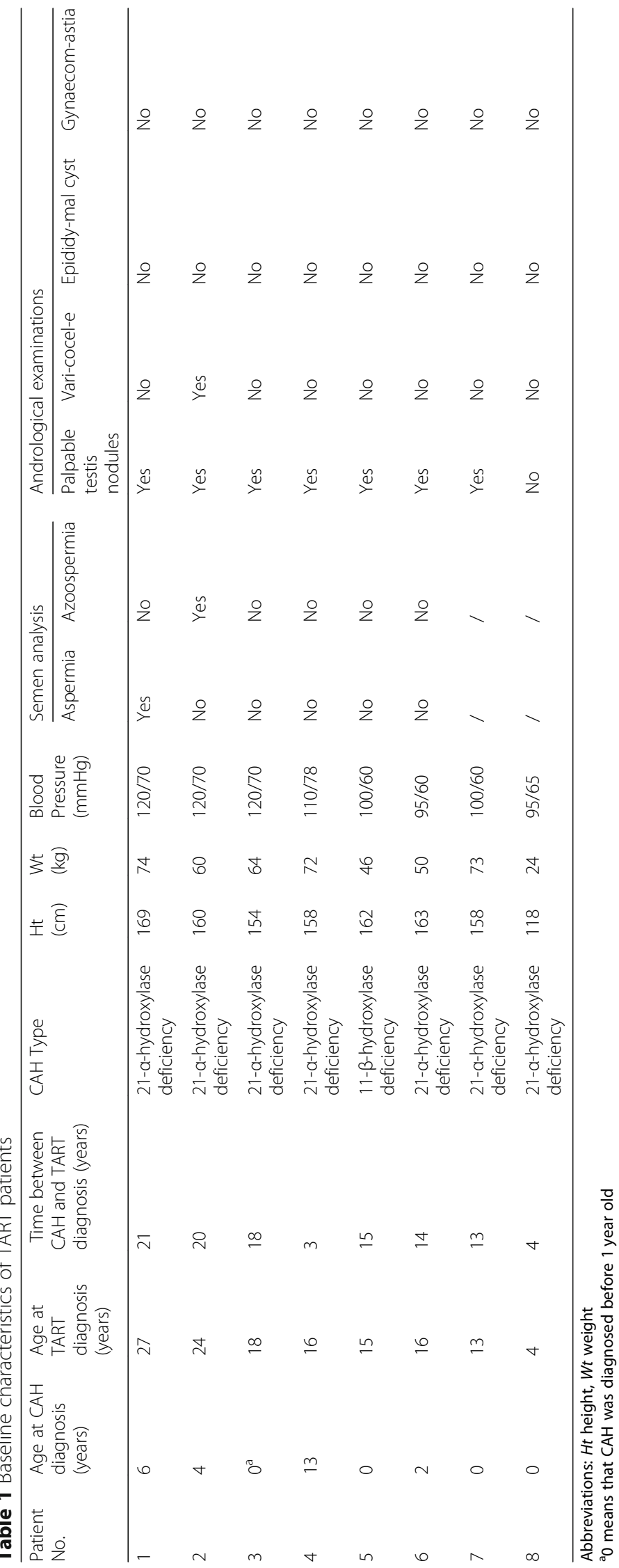


Table 2 Hormone and biomarker levels of TART patients before and after treatment

\begin{tabular}{|c|c|c|c|c|c|c|c|c|c|c|c|c|c|c|c|c|c|c|c|}
\hline \multirow[t]{2}{*}{$\begin{array}{l}\text { Patient } \\
\text { No. }\end{array}$} & \multirow[t]{2}{*}{ Treatment } & \multicolumn{2}{|c|}{$\mathrm{LH}(\mathrm{IU} / \mathrm{L})$} & \multicolumn{2}{|c|}{ FSH (IU/L) } & \multicolumn{2}{|c|}{$\begin{array}{l}\text { PRL (ng/ } \\
m L)\end{array}$} & \multicolumn{2}{|c|}{$P(\mathrm{ng} / \mathrm{mL})$} & \multicolumn{2}{|c|}{$\mathrm{T}(\mathrm{ng} / \mathrm{mL})$} & \multicolumn{2}{|c|}{$E(p g / m L)$} & \multicolumn{2}{|c|}{$\begin{array}{l}\text { ACTH(pg/ } \\
\mathrm{ml})\end{array}$} & \multicolumn{2}{|c|}{$\begin{array}{l}\text { 17-OHP(ng/ } \\
\mathrm{ml})\end{array}$} & \multirow[t]{2}{*}{$\mathrm{HCG}$} & \multirow[t]{2}{*}{ AFP } \\
\hline & & Pre & Post & Pre & Post & Pre & Post & Pre & Post & Pre & Post & Pre & Post & Pre & Post & Pre & Post & & \\
\hline 1 & Dexamethasone & 5.1 & 8.21 & 2.96 & 4.44 & 12.6 & 1 & 10.94 & 33.06 & 553.4 & 7.17 & 20 & 38 & 282 & 1 & 29.5 & 1 & $<5$ & 2.4 \\
\hline 2 & Hydrocortisone & 20.1 & / & 0.5 & / & / & / & 20 & / & 18.7 & / & 99.48 & / & 157 & / & 299.9 & / & $<0.5$ & 1.9 \\
\hline 3 & Dexamethasone & 14.34 & 12.79 & 17.29 & 24.95 & / & / & 5.44 & 2.85 & 1.71 & 2.46 & 19 & 12 & 539 & 41.2 & 84.5 & 3.92 & / & / \\
\hline 4 & Hydrocortisone & 6.41 & 0 & 6.42 & 0 & 7.24 & 35 & / & / & 25.51 & 3.66 & 38 & 240.6 & 32.4 & 14.6 & 40.1 & 19.68 & 0 & 1.7 \\
\hline 5 & Hydrocortisone & 4.44 & 8.59 & 8.21 & 10.45 & / & / & 33.06 & 5.27 & 2.17 & 6.23 & 38 & 27 & 410 & 516 & $\begin{array}{l}\text { DS: } \\
184.6\end{array}$ & $\begin{array}{l}\text { DS: } \\
200.6\end{array}$ & I & / \\
\hline 6 & Hydrocortisone & 2.66 & 11.38 & 6.3 & 6.22 & / & / & 15.3 & 6.68 & 5.54 & 6.29 & 27 & 23 & 291 & 798 & $\begin{array}{l}\text { DS: } \\
89.3\end{array}$ & $\begin{array}{l}\text { DS: } \\
74.4\end{array}$ & / & / \\
\hline 7 & Prednisone & 0.96 & 1.88 & 5.21 & 5.49 & / & / & 2.7 & 4.88 & 3.59 & 4.36 & 5 & 35 & 254 & 213 & $\begin{array}{l}\text { DS: } \\
29.0\end{array}$ & $\begin{array}{l}\text { DS: } \\
36.1\end{array}$ & $<0.1$ & 1.7 \\
\hline 8 & Hydrocortisone & 0.18 & 1.10 & 0.76 & 0.21 & / & / & 39 & 0.39 & 2.07 & $<0.1$ & 18 & $<5$ & 373 & 170 & 64.31 & 4.47 & 0.8 & 1.1 \\
\hline
\end{tabular}

Abbreviations: $L H$ luteinizing hormone, $F S H$ follicle-stimulating hormone, $P R L$ prolactin, $P$ progesterone, $T$ testosterone, $E$ estrogen, $A C T H$ adrenocorticotropic hormone, 17-OHP 17 hydroxyprogesterone, HCG human chorionic gonadotropin, AFP alpha fetoprotein, Pre pre-treatment, Post post-treatment, DS dehydroepiandrosterone-s

\section{Discussion}

In this study, we retrospectively reviewed the sonographic characteristics of TART in $8 \mathrm{CAH}$ patients, and further analyzed $123 \mathrm{CAH}$ patients from the literature. The TARTs were described mainly in several aspects: bilateral/unilateral; location; size; shape; boundary; vascularity; changes with steroid treatment. The sizes of lesions from the literature were not summarized this time because of the nonuniform descriptions. We also described the calcification of two lesions in one patient, suggesting that calcification is not an exclusive sign for malignant tumors.

The majority of TART are bilateral. Notably, we also noticed that the same characteristics were observed in bilateral lesions in every patient, including echogenicity, boundary, and vascularity. This feature is also confirmed by several other studies, for example, Wang et al. reported 15 TART patients, and 12 of $15(80 \%)$ showed exact same sonographic features of both lesions [21]; Defino et al. described 9 bilateral TARTs with same characteristics [2]; Multiple case reports also described this feature $[16,19]$. As most malignant tumors occur solitarily, it is a distinct feature for differential diagnosis. However, it is worth noticing that unilateral lesions cannot rule out TART. The reason is probably that minimal lesions may exist but are undetectable by radiological methods. Similarly, although the clear boundary is a prominent feature of TART, it is not specific enough,

Table 3 Sonographic features of testicular adrenal rests tumor in TART patients

\begin{tabular}{|c|c|c|c|c|c|c|c|}
\hline Patient No. & Lesions & Lesion size (ml) & Lesion Shape & Lesion Boundaries & Echogenicity & Vascularity & Calcification \\
\hline 1 & L & 0.21 & Round & Clear & Homo/iso* & Absent & No \\
\hline \multirow[t]{2}{*}{2} & L & 2.09 & Round & Clear & Homo/hypo & Marked & No \\
\hline & $\mathrm{R}$ & 1.52 & Round & Clear & Homo/hypo & Marked & No \\
\hline \multirow[t]{2}{*}{3} & L & 5.13 & Round & Clear & Hetero/iso-hypo & Minimal & No \\
\hline & $\mathrm{R}$ & 5.68 & Round & Clear & Hetero/iso-hypo & Minimal & No \\
\hline \multirow[t]{2}{*}{4} & L & 0.30 & Lobular & Clear & Homo/hypo & Marked & Yes \\
\hline & $\mathrm{R}$ & 0.20 & Lobular & Clear & Homo/hypo & Marked & Yes \\
\hline \multirow[t]{2}{*}{5} & L & 0.34 & Round & Clear & Homo/hypo & Marked & No \\
\hline & R & 0.18 & Round & Clear & Homo/hypo & Marked & No \\
\hline \multirow[t]{2}{*}{6} & L & 1.48 & Lobular & Clear & Hetero/iso-hypo & Marked & No \\
\hline & R & 1.83 & Lobular & Clear & Hetero/iso-hypo & Marked & No \\
\hline \multirow[t]{2}{*}{7} & L & 0.90 & Lobular & Clear & Homo/hypo & Marked & No \\
\hline & R & 0.92 & Lobular & Clear & Homo/hypo & Marked & No \\
\hline \multirow[t]{2}{*}{8} & $L$ & 1.49 & Round & Clear & Homo/hypo & Minimal & No \\
\hline & $\mathrm{R}$ & 0.47 & Round & Clear & Homo/hypo & Minimal & No \\
\hline
\end{tabular}

Abbreviations: $L$ left, $R$ right, homo homogeneous, iso isoechogenicity, hypo hypoechogenicity, hetero heterogeneous, iso-hypo hypoechogenicity mixed with isoechogenicity 


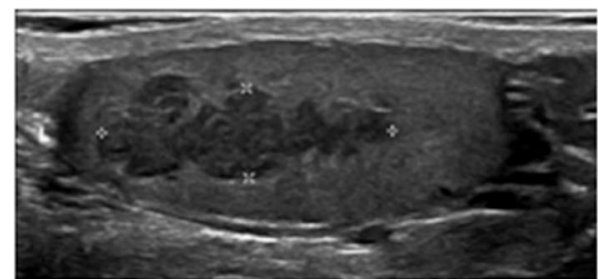

(a)

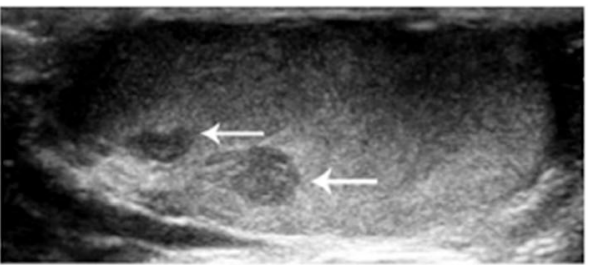

(c)

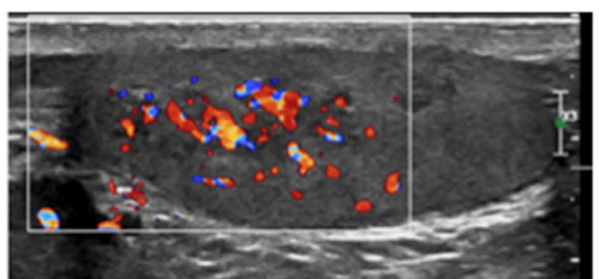

(b)

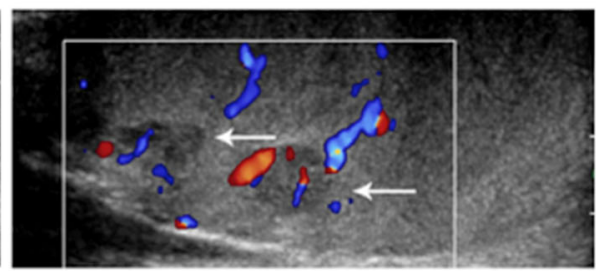

(d)

Fig. 1 Ultrasound features of TART. This is a 13-year-old CAH patient. Palpable testicular nodules were detected through physical examination and a scrotal ultrasound was therefore performed. The scrotal gray-scale ultrasound (a) and color Doppler ultrasound (b) showed homogeneous hypoechoic lesions with clear boundary on both testes with marked vascularity. Follow-up gray-scale (c) and color Doppler (d) ultrasound examination was performed after a 6-month steroid treatment, which showed a remarkable decrease in lesion size and vascularity

since other kinds of testicular tumors like seminoma, teratoma, Leydig cell tumor, can also have clear boundaries on the ultrasound.

Controversial opinions exist about the relationship between ACTH levels and the size of TARTs [7]. Some studies reported that TART cells have ACTH receptors so

Table 4 Literature review of testicular adrenal rests tumor in patients with congenital adrenal hyperplasia

\begin{tabular}{lll}
\hline Characteristics & & $\begin{array}{l}\text { Number } \\
\text { (Percentage) }\end{array}$ \\
\hline $\begin{array}{l}\text { Total number of } \\
\text { patients/lesions }\end{array}$ & $123 / 223$ \\
$\begin{array}{l}\text { Bilateral lesions } \\
\text { Located near the } \\
\text { mediastinum }\end{array}$ & & $100 / 123(81 \%)$ \\
Clear Boundaries & & $107 / 113(95 \%)$ \\
Shape & Round or oval & \\
& Lobular & $80 / 103(78 \%)$ \\
& Irregular & $75 / 106(71 \%)$ \\
Echogenicity & Hypoechogenicity & $29 / 106(27 \%)$ \\
& Heterogeneous & $2 / 106(2 \%)$ \\
Vascularity & Other types ${ }^{a}$ & $164 / 223(74 \%)$ \\
& Absent & $41 / 223(18 \%)$ \\
& Minimal & $18 / 223(8 \%)$ \\
& Moderate & $39 / 152(26 \%)$ \\
Follow-up & Marked & $25 / 152(16 \%)$ \\
& No change & $31 / 152(20 \%)$ \\
& Reduced & $52 / 152(34 \%)$
\end{tabular}

${ }^{2}$ Other types: hyperechogenicity, isoechogenicity, or anechogenicity that the tumor size is responsive to ACTH levels, while other studies suggested that other growth-promoting factors might also be involved, thereby ACTH is not the only factor effecting on the growth of TART $[6,8,35]$. In our study, a $p$-value of 0.066 was found between TART size and ACTH levels, suggesting a potential relationship may exist, even though further studies with a larger sample size are needed for the validation of our results.

In our study, most lesions showed marked blood supply. Summarized from the literature, the vascularity of TART exhibited a great diversity. Interestingly, different researches revealed completely opposite vascularity conditions, for example, in the report of Wang et al., the majority of lesions were richly vascularized, whereas in the study of Delfino et al., no blood signal was observed in a large percentage of lesions $[2,21]$. Since the vascularity assessment lacks objective values such as peak systolic velocity or resistance index in this condition, it depends mainly on the different machine settings and subjective judgment by radiologists, making it an unreliable indicator. Further studies are encouraged to provide objective parameters of vascularity for clinical use. In this circumstance, vascularity cannot become a suitable marker for diagnosis and differential diagnosis.

From the literature, shrinkage or disappearance of TARTs was observed in 64\% (50/79) lesions after steroid therapy. A few patients failed to show any changes during follow-up, and the potential reason might be poor steroid control with/without treatment. Ultrasound can be an ideal tool for TART monitoring. Previous studies have proposed that an ultrasound screening for TART should be performed in all $\mathrm{CAH}$ patients, and regular monitoring by scrotal ultrasound should be done to prevent possible infertility [36-38]. 
Besides sonographic features, TART always accompanies with prominent clinical manifestations related to $\mathrm{CAH}$, such as obesity, short stature, early hypertension, and hirsutism $[8,39]$. These clinical characteristics are easily perceived when performing ultrasound examinations or accessed by enquiring patients or their guardians. Identification of these features might increase the diagnostic confidence of TART. Normal AFP and HCG levels are also suggestive of benign tumors. However, since other testicular tumors such as Leydig cell tumors can also lead to precocious puberty in pre-pubertal males, radiologists would be very careful to make a differential diagnosis and not rely too much on clinical features [40]. Sonographically, Leydig cell tumors are mostly isolated, hypoechoic masses with peripheral vascularity [41].

There are several limitations to our study. The sensitivity and specificity of each characteristic sonographic sign were not able to be calculated; therefore, a more thorough case-control study with a larger sample size is necessary for the future. How the hormones affect TART evolvement was not able to be addressed in this study.

\section{Conclusions}

In conclusion, according to our findings, TART has several prominent features on ultrasound: [1] bilateral testicular lesions with the same manifestations [2]; located near the mediastinum [3]; clear boundary [4]; sonographic changes with steroid therapy. As a rare kind of benign tumor in the testis, TART has to be diagnosed very carefully, and a reference to typical CAH symptoms, AFP, HCG, and hormonal levels and a positive finding in adrenal glands can be of help to increase diagnostic accuracy.

\section{Abbreviations}

ACTH: adrenocorticotropic hormone; $\mathrm{CAH}$ : congenital adrenal hyperplasia; FSH: follicle-stimulating hormone; LH: luteinizing hormone; TART: testicular adrenal rests tumor

\section{Acknowledgements}

None.

\section{Authors' contributions}

All authors have contributed significantly to this paper. $L M$ and $Y X$ analyzed the data and wrote the manuscipt; LW collected data; RL, XW, YT and LZ provided professional opinions about TART and ultrasound manifestations; QZ and $J$ revised the manuscipt; and YJ designed and supervised the study. All authors read and approved the final manuscript.

\section{Funding}

None.

Availability of data and materials

The data and material can be provided if asked on a basis of good reasons.

\section{Ethics approval and consent to participate}

Written informed consent was signed by all patients or their legally authorized representatives. The Institutional Review Board (IRB) of Peking Union Medical College Hospital (PUMCH) has reviewed the protocol of this manuscript and has determined that this study is exempt from full IRB review since it is a retrospective study.
Consent for publication

All authors have read and approved the submission of the final manuscript.

\section{Competing interests}

The authors declare that they have no competing interests.

\section{Author details}

${ }^{1}$ Department of Ultrasound, Peking Union Medical College Hospital, Chinese Academy of Medical Sciences, Shuaifuyuan 1, Dongcheng District, Beijing 100730, China. ${ }^{2}$ Department of Ultrasound, Harrison International Peace Hospital, Hebei, China.

Received: 8 April 2019 Accepted: 22 October 2019

Published online: 06 November 2019

\section{References}

1. New MI. An update of congenital adrenal hyperplasia: John Wiley \& Sons, Ltd; 2012. 14-43 p.

2. Delfino M, Elia J, Imbrogno N, Argese N, Mazzilli R, Toscano V, et al. Testicular adrenal rest tumors in patients with congenital adrenal hyperplasia: prevalence and sonographic, hormonal, and seminal characteristics. Journal of Ultrasound in Medicine Official Journal of the American Institute of Ultrasound in Medicine. 2012;31(3):383.

3. Mesiano S, Jaffe RB. Developmental and functional biology of the primate fetal adrenal cortex. Endocr Rev. 1997:18(3):378-403.

4. Dahl EV. Aberrant adrenal cortical tissue near the testis in human infants. Tech Doc Rep SAMTDR USAF Sch Aerosp Med. 1961;61-61:1-10.

5. Claahsen-van der Grinten HL, Otten BJ, Stikkelbroeck MM, Sweep FC, Hermus AR. Testicular adrenal rest tumours in congenital adrenal hyperplasia. Best Pract Res Clin Endocrinol Metab. 2009;23(2):209-20.

6. Stikkelbroeck NM, Otten BJ, Pasic A, Jager GJ, Sweep CG, Noordam K, et al. High prevalence of testicular adrenal rest tumors, impaired spermatogenesis, and Leydig cell failure in adolescent and adult males with congenital adrenal hyperplasia. J Clin Endocrinol Metab. 2001;86(12):5721-8.

7. Dumic M, Duspara V, Grubic Z, Oguic SK, Skrabic V, Kusec V. Testicular adrenal rest tumors in congenital adrenal hyperplasia-cross-sectional study of 51 Croatian male patients. Eur J Pediatr. 2017;176(10):1393-404.

8. Cakir ED, Mutlu FS, Eren E, Pasa AO, Saglam H, Tarim O. Testicular adrenal rest tumors in patients with congenital adrenal hyperplasia. J Clin Res Pediatr Endocrinol. 2012;4(2):94-100.

9. Grinten CVD, Otten BJ, Hermus ARMM, Sweep FCGJ. Testicular adrenal rest tumors in patients with congenital adrenal hyperplasia can cause severe testicular damage. Fertil Steril. 2008;89(3):597-601.

10. Speiser PW. Congenital adrenal hyperplasia owing to 21-hydroxylase deficiency. Endocrinol Metab Clin N Am. 2001;30(1):31-59.

11. Avila NA, Premkumar A, Shawker TH, Jones JV, Laue L, Jr CG. Testicular adrenal rest tissue in congenital adrenal hyperplasia: findings at gray-scale and color Doppler US. Radiology. 1996;198(1):99.

12. Mikuz G. Update on the pathology of testicular tumors. Anal Quant Cytopathol Histpathol. 2015;37(1):75-85.

13. Organization WH. WHO Laboratory manual for the examination and processing of human semen, 5th edn. Geneva: World Health Organization; 2010.

14. BI-RADS ${ }^{\oplus}$ - Ultrasound. version 2. Breast Imaging Reporting and Data System (BI-RADS) atlas, 5th edn: American College of Radiology, Reston; 2013.

15. Adler DD, Carson PL, Rubin JM, Quinn-Reid D. Doppler ultrasound color flow imaging in the study of breast cancer: preliminary findings. Ultrasound Med Biol. 1990;16(6):553-9.

16. Deshpande SS, Shetty D, Saifi S. Sonographic appearance of testicular adrenal rest tumour in a patient with congenital adrenal hyperplasia. Pol J Radiol. 2017;82:526.

17. Dogra V, Nathan J, Bhatt S. Sonographic appearance of testicular adrenal rest tissue in congenital adrenal hyperplasia. Journal of ultrasound in medicine : official journal of the American Institute of Ultrasound in Medicine. 2004;23(7):979-81.

18. Fitoz S, Atasoy C, Adiyaman P, Berberoglu M, Erden I, Ocal G. Testicular adrenal rests in a patient with congenital adrenal hyperplasia: US and MRI features. Comput Med Imaging Graph. 2006:30(8):465-8.

19. Proto G, Donna AD, Grimaldi F, Mazzolini A, Purinan A, Bertolissi F. Bilateral testicular adrenal rest tissue in congenital adrenal hyperplasia: US and MR features. J Endocrinol Investig. 2001;24(7):529-31. 
20. Stikkelbroeck NM, Suliman HM, Otten BJ, Hermus AR, Blickman JG, Jager GJ. Testicular adrenal rest tumours in postpubertal males with congenital adrenal hyperplasia: sonographic and MR features. Eur Radiol. 2003;13(7):1597-603.

21. Wang Z, Yang Z, Wang W, Chen LD, Huang Y, Li W, et al. Diagnosis of testicular adrenal rest tumors on ultrasound: a retrospective study of 15 cases report. Medicine (Baltimore). 2015;94(36):e1471.

22. Avila NA, Shawker TS, Jones JV, Cutler GB, Merke DP. Testicular adrenal rest tissue in congenital adrenal hyperplasia: serial sonographic and clinical findings. AJR Am J Roentgenol. 1999;172(5):1235.

23. Nagamine WH, Mehta SV, Aruna V. Testicular adrenal rest tumors in a patient with congenital adrenal hyperplasia: sonographic and magnetic resonance imaging findings. J Ultrasound Med. 2005;24(12):1717-20.

24. Chaudhari M, Johnson EK, DaJusta D, Nahata L. Testicular adrenal rest tumor screening and fertility counseling among males with congenital adrenal hyperplasia. J Pediatr Urol. 2018;14(2):155 e1-6.

25. Depaoli R, Bartolucci F, Draghi F. Testicular adrenal rest tissue in a patient with classical congenital adrenal hyperplasia: color Doppler findings. J Ultrasound. 2013;16(2):81-4.

26. Jedrzejewski G, Ben-Skowronek I, Wozniak MM, Brodzisz A, Budzynska E, Wieczorek AP. Testicular adrenal rest tumors in boys with congenital adrenal hyperplasia: 3D US and elastography--do we get more information for diagnosis and monitoring? J Pediatr Urol. 2013;9(6 Pt B):1032-7.

27. Kim HK, Crotty E. Bilateral testicular adrenal rests in a boy with congenital adrenal hyperplasia. Pediatr Radiol. 2010;40(S1):25.

28. Kolli V, Kim H, Torky A, Lao Q, Tatsi C, Mallappa A, et al. Characterization of the CYP11A1 nonsynonymous variant p.E314K in children presenting with adrenal insufficiency. J Clin Endocrinol Metab. 2019;104(2):269-76.

29. Mazzilli R, Stigliano A, Delfino M, Olana S, Zamponi V, lorio C, et al. The high prevalence of testicular adrenal rest tumors in adult men with congenital adrenal hyperplasia is correlated with ACTH levels. Front Endocrinol. 2019;10.

30. Meena H, Jana M, Singh V, Kabra M, Jain V. Growth pattern and clinical profile of Indian children with classical 21-hydroxylase deficiency congenital adrenal hyperplasia on treatment. The Indian Journal of Pediatrics. 2019;86(6):496-502.

31. Yılmaz R, Şahin D, Aghayev A, Erol OB, Poyrazoğlu Ş, Saka N, et al. Sonography and magnetic resonance imaging characteristics of testicular adrenal rest tumors. Pol J Radiol. 2017;82:583-8.

32. Shawker TH, Doppman JL, Choyke PL, Feuerstein IM, Nieman LK. Intratesticular masses associated with abnormally functioning adrenal glands. J Clin Ultrasound. 1992;20(1):51-8.

33. Marchini GS, Cocuzza M, Pagani R, Torricelli FC, Hallak J, Srougi M. Testicular adrenal rest tumor in infertile man with congenital adrenal hyperplasia: case report and literature review. Sao Paulo Med J. 2011;129(5):346-51.

34. Arenson AM, Hamilton P, Silverberg J, Withers C, Livingstone D. Ultrasound diagnosis of testicular masses secondary to hyperplastic adrenal rests in a patient with adrenal insufficiency. J Clin Ultrasound. 1991;19(7):430-3.

35. Poyrazoglu S, Saka N, Agayev A, Yekeler E. Prevalence of testicular microlithiasis in males with congenital adrenal hyperplasia and its association with testicular adrenal rest tumors. Horm Res Paediatr. 2010;73(6):443-8.

36. Claahsen-Van dGHL, Hermus ARMM, Otten BJ. Testicular adrenal rest Tumours in congenital adrenal hyperplasia. Int J Pediatr Endocrinol. 2007;2009(1):1-8

37. Yu MK, Jung MK, Kim KE, Kwon AR, Chae HW, Kim DH, et al. Clinical manifestations of testicular adrenal rest tumor in males with congenital adrenal hyperplasia. Annals of Pediatric Endocrinology \& Metabolism. 2015;20(3):155-61.

38. Aycan Z, Bas VN, Cetinkaya S, Yilmaz Agladioglu S, Tiryaki T. Prevalence and long-term follow-up outcomes of testicular adrenal rest tumours in children and adolescent males with congenital adrenal hyperplasia. Clin Endocrinol. 2013;78(5):667-72

39. Finkielstain GP, Kim MS, Sinaii N, Nishitani M, Van RC, Hill SC, et al. Clinical characteristics of a cohort of 244 patients with congenital adrenal hyperplasia. J Clin Endocrinol Metab. 2012;97(12):4429.

40. Maxwell F, Izard V, Ferlicot S, Rachas A, Correas JM, Benoit G, et al. Colour Doppler and ultrasound characteristics of testicular Leydig cell tumours. Br J Radiol. 2016:89:1062

41. Maizlin ZV, Belenky A, Kunichezky M, Sandbank J, Strauss S. Leydig cell tumors of the testis: gray scale and color Doppler sonographic appearance. Journal of Ultrasound in Medicine Official Journal of the American Institute of Ultrasound in Medicine. 2004;23(7):959-64.

\section{Publisher's Note}

Springer Nature remains neutral with regard to jurisdictional claims in published maps and institutional affiliations.

\section{Ready to submit your research? Choose BMC and benefit from:}

- fast, convenient online submission

- thorough peer review by experienced researchers in your field

- rapid publication on acceptance

- support for research data, including large and complex data types

- gold Open Access which fosters wider collaboration and increased citations

- maximum visibility for your research: over $100 \mathrm{M}$ website views per year

At $\mathrm{BMC}$, research is always in progress.

Learn more biomedcentral.com/submissions 